\title{
ENTRE CALLAR Y NO CALLAR: DECIR LO JUSTO*
}

\author{
Manuel Atienza \\ Universidad de Alicante
}

RESUMEN. En la nueva contestación a HABA, el autor hace algunas puntualizaciones en relación con las falacias que, según este último, HABA habría cometido en el artículo que originó la polémica, para pasar luego a plantear las tres cuestiones que le parecen de mayor interés: el contraste entre una "crítica crítica» (la de HABA) y las "críticas-poco críticas» (las de la teoría estándar); el papel de las actitudes en la teoría del Derecho; y el llamado por HABA «síndrome normativista». Lo que el autor considera como el principal defecto de una concepción «realista» como la de HABA es «su incapacidad para guiar nuestras prácticas».

Palabras clave: argumentación jurídica, E. P. HABA, M. AtienZA.

ABSTRACT. In this new reply to HABA, the author makes a few points regarding the fallacies which he considers HABA included in the article which gave rise to the controversy. He then goes on to raise the three questions that he considers to be of greatest interest: the contrast between "critical critique» (HABA's) and «not-so-critical critiques» (that of the standard theory); the role of attitudes in theory of law; and that which HABA calls «normativist syndrome». It is «its inability to guide our practices» that the author considers to be the main defect in a «realist» conception like that of HABA's.

Keywords: legal argumentation, E. P. HABA, M. ATIENZA.

* Fecha de recepción: 9 de mayo de 2011. Fecha de aceptación: 13 de mayo de 2011. 
No interpretaré el título («Callar o no callar») de la contestación que
E. HABA ha dedicado a mi comentario como una invitación a la desmesu-
ra; quiero decir, a la desmesura lingüística, a la verborrea. De lo que HABA
me acusa — acusa a la teoría estándar de la argumentación jurídica- es de
callar ciertas cosas. Pero no creo que mi inteligente y amable contendiente en este amistoso debate se contentase simplemente con que yo empleara muchas páginas en contestar a todas sus objeciones. «No callar», evidentemente, no quiere decir que haya que emplear páginas y más páginas en escribir cosas que podrían caber cómodamente en un par de párrafos. E. HABA, como se ve, es escritor de prosa suelta y abundante. Yo tiendo a ser más sintético y, por ello, contestaré de nuevo a su réplica utilizando muchas menos palabras de las que él ha considerado conveniente emplear en su intervención. ¿Tendrá eso que ver únicamente con cuestiones de estilo o de actitud? ¿O refleja quizás maneras distintas de enfrentar los problemas, de construir teorías, de ejercer la racionalidad? En todo caso, lo que quisiera dejar claro es que la brevedad (relativa brevedad) de mis intervenciones en este debate no se debe a que yo tenga un menor interés en el mismo del que tiene HABA. Pero tampoco (como podría pensarse después de leer su texto) a que yo tenga cosas que callar, mientras que él estaría en una situación en la que puede decirlo todo (todo lo que resulta relevante al tema), sin callarse nada. Eso justificaría, por cierto, las diferencias de extensión entre sus intervenciones y las mías. Pero, como procuraré mostrar en lo que sigue, no se trata de eso.

2. Empezaré con algunas pocas (y breves) puntualizaciones referidas al apartado 2 del escrito de HABA en las que mi interlocutor se defiende de las falacias de las que yo le acusaba. Aclaro, por cierto, que lo de «acusación» tiene un sentido meramente metafórico. Lo que yo hacía era efectuar una movida en un juego dialéctico que tenía como objetivo que la otra parte, HABA, diera a su vez un paso que yo entendía él no había dado: dirigir y formular bien sus críticas. E. HABA no se ha limitado a defenderse del ataque sino que me ha imputado la comisión de falacias aún más graves. Y ahora me toca a mí intervenir de nuevo en el juego para mantener o no mis posiciones iniciales. Lo haré en relación con cada una de las cuatro.

2.1. A propósito de la falacia de la indeterminación, HABA entiende que no la ha cometido, puesto que él había enumerado cuáles eran los autores a los que refería sus críticas (los mismos señalados por mí) y las tesis criticadas (caracterizadas por cinco rasgos, cuatro de ellos tomados también de mí). Bueno, creo que aquí ha habido una confusión. Estos cuatro últimos rasgos (junto con otros ocho o nueve), yo los utilizaba para caracterizar no a la «teoría estándar de la argumentación jurídica», como parece haber supuesto $\mathrm{HABA}_{\mathrm{A}}$, sino a una concepción del Derecho de la que participaría una clase más amplia y heterogénea de autores, señalando además que ninguno de ellos asumía todos los rasgos que allí indicaba, aunque sí un número significativo de los mismos. No tengo mayor interés en depurar responsabilidades para ver quién ha tenido la culpa del malentendido. Constato simplemente que lo ha habido y que sigue habiéndolo. Y que ese malentendido es el que genera la discusión que HABA emprende en el apartado 3 («¿Desconocimiento de diferencias entre los autores "estándar"?») y que no merece la pena proseguir: simplemente, yo no he afirmado nunca que DworKIN o FERRAJOLI formaran parte de la «teoría estándar» de la argumentación jurídica, y a TOULMin y a PERELMAN (autores por los que HABA parece sentir mayor simpatía 
que por los otros) los califiqué en su momento como «precursores» de esa teoría, de la teoría estándar.

2.2. A E. HABA le parece inaudito, a propósito de la falacia de la exageración, que yo haya podido interpretar que él hubiera afirmado que autores como AlEXY, MACCORMICK, AARNIO o PECZENIK habían «incurrido» en el «síndrome normativista». Pues bien, el malentendido en este caso proviene del verbo «incurrir» que yo efectivamente utilizaba en mi comentario. HABA interpreta que la expresión «incurren en el síndrome normativista» (referida a los anteriores autores) implica necesariamente afirmar que ellos cometen los errores que él agrupa bajo ese rótulo («síndrome normativista») y de ahí sus ardientes protestas: la crítica que dirige a esos autores no es por lo que hacen, sino por lo que no hacen; no por lo que dicen sino por lo que callan, etc. Pues bien, es posible que yo no haya elegido el verbo adecuado, pero lo que quería decir con esa frase resulta, me parece, suficientemente claro si uno sigue leyendo el texto que HABA reproduce (las líneas que le siguen tras un punto y coma) o bien la aclaración que había hecho poco antes (al comienzo del apartado 2 de mi comentario): «Con lo de "síndrome normativista" —escribía yo entonces- HABA quiere decir que el conjunto de autores que integran la "teoría estándar" [...] se desentiende de una serie de vicios de razonamiento, de falacias que se encuentran corrientemente en los discursos de los profesionales del Derecho». Como se ve, un buen ejemplo de que, en ocasiones, una lectura atenta (o, si se quiere, «caritativa») de un texto puede ahorrar muchas páginas. El optar por uno u otro tipo de lectura puede también ser la causa de que haya autores que tiendan a ser más «callados» que otros.

2.3. En relación con la tendencia que yo le atribuyo a HABA de presentar la teoría estándar de una manera idealizada, en el sentido de afeada, él me reta a que señale «cuáles son los rasgos complementarios, precisamente los "bellos", cuya existencia yo (o sea, HABA) habría negado, o al menos disimulado de alguna manera». Tiene razón en que yo no lo había hecho entonces, pero precisamente porque entendía que él no había formulado sus críticas de manera que fuera posible propiamente una discusión al respecto. Lo hago en todo caso ahora. En mi opinión, el lector de HABA (que no lo haya sido también de los otros autores) no se hace para nada una idea adecuada de lo que puede encontrar en las obras de MACCORMICK o de AlEXY. Se sorprendería mucho, me parece, al comprobar que MACCORMICK construye su teoría a partir de casos relevantes del common law y que elabora con cuidado y rigor una serie de criterios para evaluar las argumentaciones jurídicas (las nociones de universalidad, coherencia, etc.) que son, precisamente, potentes instrumentos para la crítica (fundada) de las argumentaciones judiciales que de hecho tienen lugar. $\mathrm{O}$ al enterarse de que la teoría de la argumentación jurídica de ALEXY — o ciertos elementos de la misma- está sirviendo de guía para muchos tribunales en Europa y en América latina y también para quienes critican las decisiones emanadas de los mismos; lo que hace pensar en que la teoría quizás no se haya elaborado tan de espaldas a la realidad, sino teniendo muy en cuenta la práctica real de la argumentación jurídica y la necesidad de mejorarla. En definitiva, se trata de obras que, aunque parciales y criticables en varios sentidos, nos permiten entender mejor muchos aspectos de las argumentaciones jurídicas y contribuyen también a mejorar nuestras prácticas jurídicas. Y esto, me parece, no se sigue de la lectura de HABA. 
2.4. En fin, por lo que hace a lo del «síndrome del crítico», la verdad es que la lectura de los últimos comentarios de HABA me llevan más bien a ratificarme en mi diagnóstico. Si se me permite el tono festivo: la pretensión de que sólo él (y algunos otros pocos autores a los que se refiere como «realistas») son capaces de hablar sobre lo que los otros callan porque al parecer estos últimos participan (participamos) en una especie de «conspiración del silencio» para defender no se sabe qué intereses académicos, parece verdaderamente excesiva y propia de estados más bien febriles, en los que el paciente tiende a deformar la realidad para adecuarla a la imagen de la misma que él ha creado en su imaginación. Sobre esto volveré más adelante.

3. Pero vayamos ya a lo que verdaderamente importa. En la réplica de HaBA yo he encontrado tres cuestiones que me parece de interés discutir. Una se refiere al contraste que él establece entre la «crítica crítica» (digamos, la suya) y las «críticaspoco-críticas» (las mías y las de los autores a los que él engloba bajo el rótulo de «teoría estándar de la argumentación jurídica»). Otra tiene que ver con las actitudes y con el papel que las mismas deben - o no- jugar en la teoría, en la teoría del Derecho. Y la última concierne al ya famoso «síndrome normativista», en cuanto HABA, si le he entendido bien, considera que ahí radica el núcleo de sus ideas sobre la argumentación jurídica y de su crítica a los autores de la concepción estándar.

3.1. La diferencia entre la «crítica crítica» y las «críticas-poco críticas» la traza HABA de la siguiente manera: «Por un lado (la "crítica crítica"), las críticas de alcance estructural (voy a llamarlo así), esencialmente "incómodas"; suelen ser descalificadas como "negativas" por parte del establishment respectivo. Por otro lado (las "críticaspoco-críticas"), las críticas que son antes bien circunstanciales, poco o nada "molestas", se suelen calificar como "positivas" o "constructivas"; son "suaves", diría yo, más allá de que hasta puedan ser muy minuciosamente analíticas algunas de ellas —eso sí, lo son con respecto a detalles que no "duelen" mayormente al establishment»-—.

Como antes decía, a mí me adscribe, aunque con alguna duda, al grupo de los autores «críticos-poco-críticos» o «acríticamente críticos». Y la duda, creo, se la ha planteado a HABA algo que yo escribí en un libro titulado La guerra de las falacias y con lo que él está de acuerdo. Decía allí que consideraba la filosofía como «un arte de la refutación» y que «el saber que proporciona... es, por ello, más negativo que positivo». La filosofía, añadía, «no nos enseña tanto a conocer la verdad, cuanto a reconocer el engaño y, por tanto, a no ser engañados».

Pues bien, sigo sintiéndome básicamente identificado con esa definición de la filosofía (sobre la que J. MugueRZA hace algunas interesantes consideraciones en el prólogo del libro recién mencionado), pero es cierto que ese planteamiento no es exactamente el que alguien podría encontrar en mis trabajos sobre argumentación jurídica. Mejor dicho, es el planteamiento que subyace al libro de La guerra de las falacias, porque el mismo contiene una serie de artículos de periódico en los que yo trataba de mostrar las falacias, los errores de argumentación que suelen aparecer en las discusiones públicas sobre cuestiones de actualidad y que, por ello, se constituyen en un obstáculo para la discusión racional. Pero no el que inspira el conjunto de trabajos que he publicado sobre argumentación jurídica y en los que la vertiente «constructiva» (y no sólo la «destructiva») tiene un peso considerable. En mi opinión, las tres grandes preguntas a las que debe dar respuesta una teoría de la argumentación jurídica son éstas: cómo 
analizar una argumentación, cómo evaluarla, cómo argumentar. Y para lograr entender y llevar a cabo adecuadamente esas tres operaciones, uno no puede limitarse simplemente a develar errores; no puede ejercer simplemente el tipo de crítica que HABA llama estructural. Dicho de otra manera, la teoría de la argumentación jurídica (y la teoría del Derecho), tal y como yo la(s) entiendo, no puede(n) prescindir del punto de vista interno característico de un aceptante (aunque sea «moderadamente interno», «hermenéutico», como quiera llamársele). Y esto es así porque, de otra manera, la teoría del Derecho (y estoy pensando en la teoría del Derecho de los Estados constitucionales) no podría cumplir la que, entiendo, es su función fundamental: contribuir a mejorar el Derecho y las instituciones sociales.

En mi opinión, la teoría del Derecho (como también —incluso con más razónlas diversas dogmáticas jurídicas) no puede construirse con pretensiones exclusivamente descriptivas y explicativas. Su función es, sobre todo, normativa, esto es, debe ser capaz de guiar la práctica, las diversas prácticas jurídicas. Mi crítica al realismo jurídico o a cierto realismo jurídico (el de autores como FrANK, como A. NIETO y creo también que como HABA; no valdría, sin embargo, para otros realistas como el «segundo LLEWELLYN») es que no puede dotar de sentido al Derecho, orientar a los juristas en su trabajo. Esos autores pueden quizás aspirar a no ser engañados, pero tienen que resignarse a quedarse fuera de un juego —el del Derecho— en el que ellos no pueden participar porque son radicalmente críticos con el mismo. Digamos, son simples comentaristas, observadores de un juego en el que no pueden - no deseanentrar porque, en el fondo, consideran que el mismo no puede ser jugado respetando las reglas del «fair play».

A pesar de ello, yo creo que las críticas efectuadas desde ese punto de vista (al menos, algunas de ellas; digamos, las más «realistas», en uno de los sentidos de la expresión) pueden ser útiles y, en consecuencia, deben ser tenidas en cuenta por los participantes en el juego (que, por ejemplo, en el caso del fútbol incluiría tanto a los jugadores propiamente dichos como a los entrenadores y el resto del personal «técnico» y a los espectadores y aficionados que se hacen cargo de las «servidumbres» del juego: por ejemplo, al diseñar una estrategia hay que partir de que no se trata sólo de jugar bien, sino también de jugar para ganar, etc.). Lo que no parece posible es que esas críticas se asuman como la guía central de la conducta de los participantes. Ello no quiere decir, por cierto, que los participantes no puedan adoptar una actitud crítica o que estén condenados a la «crítica-poco-crítica» a la que se refiere HABA. Dependiendo de las circunstancias, sus críticas deberán ser más o menos radicales y, llegado el caso, deben ser capaces de llegar hasta críticas de alcance estructural. Pero lo que debe guiar esa graduación no ha de ser el propósito de resultar «molesto» o «incómodo» para el establishment, como tampoco el temor a que sus comentarios puedan ser calificados de «crítica destructiva» o de «actitud negativa». De lo que se trata es de mejorar un juego, una práctica. En nuestro caso, la del Derecho del Estado constitucional. Las concepciones del Derecho realistas (como la de HABA) deben ser juzgadas también en relación con ese objetivo.

3.2. Al final de su comentario (en el Corolario), HABA sugiere que el desacuerdo entre nosotros dos no se sitúa en el plano de las creencias (de las ideas), sino en el de las actitudes. No lo hace para buscar, digamos, una reconciliación entre nuestras 
posturas, sino para acusarme de haber «pasado por alto» esa distinción aunque al mismo tiempo piensa que «seguramente» conozco «muy bien la capital diferencia que existe entre dichas dos grandes clases de desacuerdos»; pero yo habría efectuado mi comentario eludiendo llevar a cabo un debate sobre ideas y planteando en su lugar una contraposición entre actitudes con el propósito de recomendar unas de ellas (las mías frente a las de HABA). Ahora bien, las actitudes son para HABA «emociones, pautas de valor», «cuestión de gustos», sobre las que no se puede discutir racionalmente, aunque sí es posible hacerlo sobre las ideas en las que las mismas (o sea, las emociones, los valores, los gustos) se basan. El terreno de la racionalidad queda limitado para él a las cuestiones empírico-descriptivas (bien se refieran a hechos particulares o generales) o de naturaleza lógico-formal (digamos verdades formales). De manera que los únicos criterios de racionalidad serían la «veracidad empírica» y la «coherencia lógica». Una idea de racionalidad que, obviamente, recuerda mucho a la sostenida por el filósofo neopositivista A. J. AYER en un libro de los años treinta del siglo XX; según AYER — como es bien sabido-, los enunciados lingüísticos pueden ser bien analíticos (verdaderos por definición), bien empíricos (verificables recurriendo a la experiencia), o bien metafísicos (carentes de sentido, porque ni son verdaderos por definición ni son tampoco verificables).

En su comentario, HABA no se refiere, que yo recuerde, a la metafísica. Pero aclara que, en su opinión, no es posible recurrir a ninguna noción como la de razonabilidad que, en los últimos tiempos (en realidad, no tan últimos: RECASÉNS SICHES la empleó ya -inspirándose en ORTEGA - en los años cincuenta del siglo XX), ha sido invocada por muchos filósofos y iusfilósofos para ampliar el campo de la razón; HABA señala a este respecto que los términos «racional» $\mathrm{y}$ «razonable» «carecen de contenido descriptivo bien determinado, intersubjetivamente unívoco entre los locutores jurídicos», por lo cual son «fórmulas vacías» y que cumplen en el discurso jurídico una función simplemente «persuasiva».

En fin, para HABA, la decisión de optar por una «crítica crítica» o por una «críticapoco-crítica» sería una cuestión de actitudes. Y a propósito de las mías, él constata, a la luz de mi anterior comentario en esta polémica, que no me «gusta —actitud — para nada que la Teoría del Derecho se ocupe, cuando ésta estudia los razonamientos jurídicos profesionales, de poner inconfundiblemente "el dedo en la llaga" de aquellos elementos de juicio descriptivos específicos — ¡ideas! — que son del orden ( ¡realismo jurídico!) a que pertenecen los aspectos subrayados en mi artículo». Y añade: «De hecho tal actitud forma parte decisiva, sea conscientemente o no, del programa de trabajo realizado por los estudios de la teoría "estándar" en general. Todo apunta a que la actitud académica de ATIENZA, cualesquiera sean sus ideas, va dirigida a homologar ese "buen callar" como programa ampliamente dominante para llevar a cabo dichos estudios».

Bueno, este último párrafo constituye, me parece, una manifestación bastante clara del «síndrome del crítico» al que antes me refería. Supongo que podría ocurrírseme al respecto algún comentario sarcástico y quizás incluso ingenioso para salir al paso de las insinuaciones de HABA, pero prefiero no intentar esa vía..., aunque sea también una forma de «callar». Simplemente diré que hay una explicación a por qué muchos teóricos del Derecho no siguen el mismo camino que HABA, y que no tiene que ver con 
ningún tipo de actitud claudicante, vergonzosa, etc., como él parece suponer: se trata, como he procurado mostrar en el anterior punto, de que hay razones para pensar que ésa no es la vía más prometedora para hacer teoría del Derecho o teoría de la argumentación jurídica.

Por lo demás, considero que la sugerencia de HABA es, por lo menos parcialmente, acertada. Dejando a un lado los malentendidos a los que antes me referí, yo no creo que él cometa errores lógicos o errores empíricos en lo que afirma; mejor dicho, creo que algunas de sus afirmaciones empíricas (en el siguiente apartado me referiré a ellas) están hechas más bien a ojo de buen cubero, pero esto no es importante a los efectos que ahora me interesan. Quiero decir que si me parece cuestionable el modelo de teoría del Derecho (de teoría de la argumentación jurídica) que parece defender HABA no es naturalmente porque me parezca irracional, sino porque lo juzgo poco razonable. Añado además que lo razonable, en mi opinión (y en la de todos cuantos usan esa expresión), tiene que ver con valores (si se quiere, con actitudes), pero yo no creo que hablar de valores (y por tanto de actitudes) sea simplemente una cuestión de gustos y de emociones.

Me parece que, en efecto, éste es el punto fundamental que nos separa: una concepción más o menos amplia de la racionalidad práctica. La de HABA, en mi opinión (como, en general, la del positivismo lógico), es demasiado estrecha y resulta manifiestamente inadecuada cuando se la usa en el campo del Derecho. Por supuesto, HABA tiene razón en que el concepto de «razonabilidad» no tiene un «contenido descriptivo bien determinado». Pero si usáramos este criterio para determinar qué conceptos (o qué expresiones) podemos usar en nuestros discursos (en los de tipo jurídico, moral o político), habría que llegar a la conclusión de que son muchos los que tendríamos que suprimir. Es posible que alguien como HABA estuviera dispuesto a dar ese paso, pero me parece que eso no arregla las cosas, esto es, no dice nada en contra del uso de conceptos como «razonabilidad», «dignidad», «autonomía», etc. Pues no se trata de que alguien pueda arreglárselas sin esos conceptos (los carentes de «un contenido descriptivo bien determinado»). Se trata de que sin ellos nos quedaríamos sin algunas de nuestras prácticas, como la discusión racional o la motivación de las sentencias. Y éste, me parece a mí, es el verdadero quid de la cuestión.

No pretendo hacer aquí un análisis de la noción de «razonabilidad» (para lo que, por cierto, no podría prescindirse de algunos trabajos del propio HABA), pero quizás un ejemplo pueda servir para explicar por qué considero que la razonabilidad es un presupuesto de la discusión racional. En los últimos tiempos se ha discutido mucho sobre la justificación o no de investigar con células madre procedentes de embriones (o de preembriones: el embrión hasta el día 14 de su desarrollo). La Iglesia católica, como es bien sabido, se opone a ello porque entiende que la vida humana empieza desde el momento de la concepción: o sea, entiende que el valor moral de un cigoto es equivalente - pongamos - al de un recién nacido o al de una persona adulta. Los obispos, el Papa, etc., no cometen ninguna falacia (o pueden no cometerla) al argumentar a favor de esa postura. Y la misma no puede combatirse simplemente con argumentos lógico-formales o aduciendo enunciados de tipo empírico (aunque pueda ayudar a ello). La postura de la Iglesia al respecto no es irracional en sentido estricto, pero yo diría que es irrazonable, lo que en cierto modo es todavía peor. Y lo es porque al partir 
de las premisas de las que parte impide que pueda haber un debate racional sobre ese tema (puesto que apela a premisas que presuponen un acto de fe y, en consecuencia, no pueden servir como razones para los no creyentes), impide que pueda llegarse a algún acuerdo que permita resolver el problema (al menos en el nivel de las normas jurídicas). Ya sé que la noción de razonabilidad que estoy utilizando no es muy precisa, pero el anterior argumento tiene, con todo, sentido. Abre un cauce para la discusión racional, para poder llegar a entenderse en relación con un problema que necesita una solución. Ahora bien, si uno se enfrentara a ese debate con la actitud de HABA (armado de su concepto estricto de racionalidad), me temo que no es mucho lo que podría decir. Mejor dicho, quizás pudiera decir muchas cosas, pero al final tendría que reconocer que la postura de la Iglesia, como la de los laicos, se basa en juicios últimos de valor que quedan por igual al margen de la razón.

No hace falta, por lo demás, ir a un caso que puede considerarse extremo para ver lo insatisfactorio que resulta una concepción de la racionalidad como la de HABA. Dado que los juicios de valor son omnipresentes en el razonamiento jurídico, la postura de autores «realistas» como HABA lleva necesariamente a sostener que los jueces no pueden propiamente (al menos en muchos casos) justificar sus decisiones. El Derecho estaría gravemente indeterminado porque las decisiones judiciales dependen de juicios de valor que consisten en actitudes, en emociones que, en sentido estricto, no son susceptibles de enjuiciamiento racional. O sea, cuando dos jueces (dos juristas) discrepan en cuanto a cuál es la solución jurídica a un caso, y en la medida en que ello dependa (como suele ocurrir) de juicios de valor, no cabría hablar de que una de las respuestas sea la correcta: con lo que aquí nos encontraríamos sería con un desacuerdo de actitudes, que no puede resolverse racionalmente. Lo cual supone negar que la práctica de la justificación judicial de las sentencias tenga sentido; o, dicho más matizadamente: la motivación de las sentencias (al menos, de muchas de ellas) tendría que consistir simplemente en exponer con claridad los argumentos, las razones, puesto que sobre el fondo de las razones no cabría propiamente una discusión racional. De nuevo, es posible que alguien como HABA esté dispuesto a aceptar que una buena parte de nuestras prácticas jurídicas carece de sentido, se basa en mitos, etc. Pero el problema (uno de los problemas) de pensar así es que, por definición, tampoco él estaría en condiciones de sugerir otras prácticas que poner en lugar de las anteriores y que no necesitaran referirse a juicios de valor, actitudes, etc.; o sea, cualquier tipo de práctica, de práctica jurídica sería, me temo, irracional o no racional. De manera que, puesto que no podemos prescindir de tener prácticas de algún tipo, lo mejor que podemos hacer es ver cómo podemos dar sentido a las que tenemos: cómo podemos arreglárnoslas para conseguir con ellas fines valiosos y (a través de una crítica de mayor o menor calado según los casos) para mejorarlas.

3.3. Como antes decía, las ideas fundamentales de E. HABA sobre la argumentación jurídica parecen concentrarse en torno a lo que llama el «síndrome normativista» y podrían sintetizarse así (serían las presuposiciones de las cuestiones a las que considera que yo debería haber contestado - y no contesté- en mi anterior comentario): 1) esos vicios (recuérdese: poner el énfasis en las cuestiones terminológicas, no distinguir «es» $\mathrm{y}$ «debe», recurrir a conceptos indeterminados o a fórmulas vacías, etc.) son recurrentes en la práctica de la argumentación jurídica; 2) cada uno de esos vicios constituye una falacia que atenta contra la racionalidad del argumento en que aparece; 
3) los vicios en cuestión resultan decisivos para fundamentar una determinada conclusión jurídica; 4) los partidarios de la teoría estándar de la argumentación jurídica callan esos vicios que los «realistas» revelan; 5) términos como «racional» y «razonable» carecen de contenido descriptivo bien determinado, son fórmulas vacías con función meramente persuasiva, y 6) los teóricos estándar manejan un discurso en el que no aparece bien diferenciado lo prescriptivo-ideal de lo empírico-descriptivo.

Pues bien, en mi anterior comentario yo señalaba que los «vicios» a los que HABA se refiere son, podríamos decir, patrimonio común del pensamiento analítico, de manera que no había razón para pensar que los autores de la teoría estándar (aclaremos, autores como AARNIO, ALEXY, MACCORMICK o PECZENIK: todos ellos iusfilósofos de formación analítica) se hayan «desentendido» de ellos. Decía también que no me constaba que ninguno de ellos se hubiese interesado por el estudio de las falacias. Pero es evidente, por ejemplo, que alguno de los «vicios» a los que se refiere HABA están recogidos en alguna de las reglas del discurso racional sistematizadas por ALEXY (las dirigidas a evitar las imprecisiones lingüísticas, por ejemplo). Y no me cabe ninguna duda (aunque no me he dedicado a estudiarlo; no sé si merecerá mucho la pena hacerlo) que la denuncia de algunos de esos errores de razonamiento puede encontrarse, por ejemplo, en las obras de AARNIO sobre Derecho civil finlandés. Es verdad, en todo caso, que no prestaba mucha atención al dichoso síndrome, de manera que lo haré ahora. Centrémonos, entonces, en las ideas de HABA sobre la argumentación jurídica, que espero haber caracterizado bien en el párrafo anterior. Mis comentarios al respecto son los siguientes:

1) Esas ideas de НАBA (o algunas de ellas: las que tienen un alcance empíricodescriptivo) no parecen ser la consecuencia de alguna investigación de naturaleza empírica efectuada con métodos muy rigurosos. Antes decía que eran más bien observaciones hechas «a ojo de buen cubero»: la experiencia y las intuiciones de HABA le llevan, por ejemplo, a pensar que los vicios en cuestión (o alguno de ellos) tienen un peso decisivo en la presunta fundamentación de las decisiones judiciales. ¿Pero qué es lo que le hace pensar así? ¿A qué tribunales se refiere? ¿De qué país, de qué instancia, sobre qué materia? ¿Hay realmente algún trabajo «empírico» fiable que permita con fundamento generalizar como HABA lo hace? Lo dudo.

2) Mi experiencia me lleva, por el contrario, a pensar de otra manera. En primer lugar, que no se puede generalizar en este terreno, dada la enorme variedad de contextos de argumentación (y de argumentación judicial) existente. En segundo lugar, que conviene ser cauto a la hora de creer haber identificado una falacia. La comisión de una falacia es siempre una cuestión contextual; muchas veces creemos que alguien ha cometido una falacia porque ha dejado sin expresar una premisa que, sin embargo, podría entenderse que estaba implícita; otras veces, porque interpretamos equivocadamente que una frase dice lo que realmente no dice (algún ejemplo de esto lo hemos visto en el transcurso de este debate: no importa si cometido por HABA o por mí), etc. $\mathrm{Y}$ en tercer lugar, que en los casos jurídicos difíciles, importantes, pueden aparecer argumentos falaces, pero el centro de la discusión, lo que los hace difíciles, no suele radicar en eso, sino en una discrepancia sobre teoría de la interpretación o de la prueba o sobre teoría moral y política (discrepancias que no se reducen a cuestiones de palabras, a confusiones entre niveles de lenguaje, etc.). 
3) Como anteriormente he señalado, me parece dudoso que todos los vicios denunciados por HABA lo sean en realidad. Quiero decir, es cierto, por ejemplo, que expresiones como «racional» $\mathrm{y}$ «razonable» pueden usarse como fórmulas vacías. Pero está por ver que no exista un uso legítimo de esos términos (como también de «dignidad», «autonomía», etc.). En general, lo que HABA considera como vicios de razonamientos se basa en una teoría muy estrecha de la racionalidad que, como creo haber mostrado, resulta cuestionable.

4) El afán de HABA por diferenciar con precisión los elementos descriptivos y prescriptivos de las argumentaciones jurídicas me parece equivocado en el siguiente sentido. Es cierto que en ocasiones puede - y debe- hacerse esa distinción, pero no creo que la misma tenga la importancia que él supone. El método más adecuado para el estudio de las argumentaciones judiciales es probablemente uno de naturaleza reconstructiva (el que siguió, por ejemplo, MACCORMICK) que combina elementos descriptivos y prescriptivos: a partir del análisis de las argumentaciones de ciertos jueces se construye un modelo de lo que sería una buena argumentación.

5) HABA nos debe una explicación de por qué, en su opinión, los teóricos de la teoría estándar (y, al parecer, también yo) no tienen (tenemos) más remedio que callar acerca de lo que, al parecer, él sí puede hablar. Sugiere la posible existencia de intereses académicos o de algún otro tipo (en todo caso, «siniestros», para emplear una expresión de BENTHAM). Pero en esto vendría bien, creo, una mayor explicitud. ¿No estará, por cierto (y entre otras cosas), sobrevalorando el poder de lo académico? ¿Por qué cree que nos puede «doler» tanto lo que él escribe?

6) Yo no tengo duda - lo repito una vez más - de que la aproximación «realista» al Derecho y a la argumentación jurídica aporta elementos de gran valor. Y tampoco, por supuesto, de que la teoría de las falacias es un capítulo importante de la teoría de la argumentación jurídica. Lo que no me parece es que debamos suscribir «in toto» una teoría de esa especie: como la defendida por HABA. Su principal defecto, en mi opinión, es su incapacidad para guiar nuestras prácticas.

4. Quizás a E. HABA le parezca que con todo lo anterior yo no he hecho otra cosa que evadir la cuestión. De hecho, el principal propósito con el que he escrito este nuevo comentario ha sido el de desplazar la discusión hacia un terreno distinto a aquel en el que estaba planteada. En mi descargo puedo decir que lo he hecho porque éste de ahora me parece más fructífero. Pero, por lo demás, estoy perfectamente dispuesto a recibir una nueva andanada de críticas de todos los tipos que HABA tenga a bien dedicarme. No me extrañaría tampoco que no pocos lectores consideren que me las tengo bien merecidas. 